\title{
RMetS
}

Royal Meteorological Society

\section{Convective boundary-layer structure in the presence of wind-following swell}

\author{
Erik Olof Nilsson, ${ }^{\text {a }}$ Anna Rutgersson, ${ }^{\mathrm{a}}$ Ann-Sofi Smedman ${ }^{\mathrm{a}}$ and Peter P. Sullivan ${ }^{\mathrm{b} \dagger}$ \\ ${ }^{a}$ Department of Earth Sciences, Uppsala University, Sweden \\ ${ }^{\mathrm{b}}$ National Center for Atmospheric Research, Boulder, CO, USA
${ }^{\star}$ Correspondence to: E. O. Nilsson, Department of Earth Sciences, Uppsala University, Villavägen 16, 75236 Uppsala, Sweden. E-mail: erik.nilsson@met.uu.se
${ }^{\dagger}$ The contribution of this author to this article was prepared as part of his official duties as a US Federal Government employee.

The marine boundary layer is known to be influenced by fast long ocean swell waves travelling away from their generation area, where they were initiated by momentum transferred to the ocean wave field during storms. The atmospheric boundary layer during wind-following swell and various stability states has been investigated using large-eddy simulation (LES) data. The dominant energy-containing motions in the near-neutral atmospheric boundary layer over flat terrain are known to be dominated by near-ground shear-induced regions of high- and low-speed flow. Wind fields and momentum fluxes from LES for swell-dominated situations have been used to interpret field measurements suggesting that these motions are disrupted by effects related to the underlying wave field in the presence of swell waves. Statistical analysis and visualization are used to further describe the effects of stratification during swell for convective boundary-layer winds and fluxes. A mechanism for transport of momentum to the upper levels of the boundary layer is suggested from interpretation of LES data. Coherent detached eddies from the directly wave-induced motions near the surface are found to maintain an upward momentum transfer. This mechanism is found to strengthen during stronger swell conditions and also during slightly convective conditions. In this way, it is argued that processes related to both the wave field and surface convection can have a significant influence on the global structure of neutral and convective boundary layers during swell. This has implication for the turbulence length-scales during wind-following swell. Copyright (C) 2012 Royal Meteorological Society

Key Words: $\quad$ surface gravity waves; large-eddy simulation; turbulence length-scales; air-sea interaction Received 22 July 2011; Revised 21 December 2011; Accepted 24 December 2011; Published online in Wiley Online Library 31 January 2012

Citation: Nilsson EO, Rutgersson A, Smedman A-S, Sullivan P. 2012. Convective boundary-layer structure in the presence of wind-following swell. Q. J. R. Meteorol. Soc. 138: 1476-1489. DOI:10.1002/qj.1898

\section{Introduction}

Ocean waves are the most obvious phenomena of air-sea interaction processes, and their impact on winds and turbulence in the marine atmospheric boundary layer $(\mathrm{ABL})$ is an active area of research. Turbulent pressure fluctuations in the air can initiate ripples on the water surface (Phillips, 1957) which grow into wind-driven waves through a relatively poorly understood mechanism (Hristov et al., 2003). When fast, long waves propagate away from their generation area after the passage of storm fronts, they are called swell waves and can propagate long distances with very small dissipation. Large-eddy simulations (LESs) and field measurements have shown that swell waves can 
transfer momentum upwards during strong swell and a changed turbulence structure in the ABL emerges compared with boundary layers over wind-driven waves and flat or hilly terrain.

\subsection{Reduced friction during swell}

The predominance of swell waves on the world oceans has been shown in recent wave climate studies (Hanley et al., 2010; Semedo et al., 2011). It was shown that swell is prevalent almost everywhere and all the time, except in a few enclosed basins and coastal areas. However, much of previous research has focused on situations with wind sea or growing sea conditions, when the local wave and wind fields typically are more strongly coupled to each other. Several recent articles, on both modelling and field observations, have focused on swell waves and their interactions with turbulent flow in air and water.

Possible widespread occurrence of 'super smooth' flow over the ocean could be of considerable interest from a global climatological viewpoint (e.g. Kitaigorodskii, 1973; Donelan, 1990). Observations of situations with very low surface friction and even, sometimes, momentum flux directed from the water surface to the atmosphere (during swell conditions) have been made in many previous studies (e.g. Davidson and Frank, 1973; Makova, 1975; Antonia and Chambers, 1980; Smedman et al., 1994, 1999, 2009).

Grachev and Fairall (2001) refer to measurements by Edson and Fairall (1998) who reported upward momentum flux events during the Marine Boundary Layer (MBL) experiment. Positive values of momentum flux were obtained at R/V Wecoma and R/P FLIP when Wecoma was within $50 \mathrm{~km}$ of FLIP. Simultaneous measurements from two separate platforms have thus shown that upward momentum flux can exist over large areas of the open ocean.

The layer directly influenced by the waves is called the wave boundary layer (WBL). From previous model and theoretical estimates (e.g. Janssen, 1989; Makin and Mastenbroek, 1996) the thickness of the WBL was found to be typically only one to two wave heights $[\mathrm{O}(1 \mathrm{~m})]$, i.e. a small fraction of a wavelength. However, there are more recent studies indicating that the layer directly or indirectly influenced by waves is significantly deeper. Hristov et al. (2003) used a linear filter (Hristov et al., 1998) to identify the wave-induced airflow from measurements of wind velocities and ocean surface elevations and found support for the 'critical layer' theory by Miles (1957), emphasizing the importance of the wave field controlling the wave-induced momentum flux.

The nature of wave-induced effects has been studied in idealized laboratory conditions over mechanically generated monochromatic waves (e.g. Harris, 1966; Lai and Shemdin, 1971) revealing that surface waves can transport momentum upwards into the atmosphere with the aid of pressure fluctuations. Also direct numerical simulation (DNS) has been used to conduct high-fidelity computational fluid dynamics experiments of such situations (Sullivan et al., 2000; Rutgersson and Sullivan, 2005). Modelling with second-order closure models (Gent and Taylor, 1976) and large-eddy simulations (LESs) have also provided insights to such turbulent flows. Sullivan and McWilliams (2010) reviewed the dynamics of wind and currents coupled to surface waves and discussed the effects of wave motions that pump wind eddies that control fluxes across the lower atmosphere. DNS flow visualization of horizontal velocity fields illustrates wind-wave coupling. The low-speed streaks characteristic of flat-wall boundary layers are disrupted by the imposed waves over a depth of about one wavelength, which contradicts the traditional view of a shallow-wave boundary layer.

\subsection{Unstably stratified flows over flat terrain}

Previous LES investigations (e.g. Moeng and Sullivan, 1994; Khanna and Brasseur, 1998; Conzemius and Fedorovich, 2006) have explored the relative roles of buoyancy and shear in a wide range of $A B L$ states and have shown how the neutral ABL changes its character for more convective states over flat terrain. An extensive review of the conceptual understanding of wind shear in convective boundary layers (CBLs) is found in Fedorovich and Conzemius (2008) using a variety of different approaches including numerical simulations, field measurements and laboratory experiments to investigate CBLs under conditions of wind shear.

During neutral conditions the dominant shear-induced motions are streamwise low-speed motions close to the ground that align with the mean wind and are separated by less streaky high-speed motions. In moderately convective boundary layers, shear and buoyancy interact and can form large-scale turbulent motions sometimes forming longitudinal roll vortices that align with the mean wind. The vertical wind field is directly coupled to the temperature field through buoyant forces, with updraughts originating as small-scale thermal plumes near the ground that grow in horizontal scale with distance from the ground (e.g. Khanna and Brasseur, 1998). These plumes can then merge with neighbouring plumes to form larger-scale regions of upward-moving warmer fluid in the mixed layer, with broader regions of gentler downward-moving cooler fluid separating the updraughts. Buoyancy-induced updraughts and downdraughts are also responsible for much of the vertical flux of momentum, heat and passive scalars (Khanna and Brasseur, 1998) in the CBL.

Wind shear and convection are the two important forcing mechanisms for turbulent flows in general. Monin-Obukhov similarity theory relates fluxes and vertical profiles of wind and temperature to these forcing mechanisms over flat homogeneous terrain. The Obukhov length $L$ is a length-scale with its absolute value approximately equal to the height where mechanical and thermal production of turbulent energy are equal:

$$
L=-\frac{u_{*}^{3} T_{0}}{g k \overline{w^{\prime} \theta_{v}^{\prime}}},
$$

where $u_{*}$ is the friction velocity, $\overline{w^{\prime} \theta_{v}^{\prime}}$ is the kinematic virtual heat flux, $\theta_{v}$ is the virtual potential temperature, $\kappa=0.4$ is the von Kármán constant and $g / T_{0}$ is the buoyancy parameter where $T_{0}$ is the average surface layer temperature and $g$ is the acceleration of gravity. The nondimensional heights $z / L$ and $z_{\mathrm{i}} / L$ have frequently been used as similarity variables in analysis of measurements and models to diagnose atmospheric stability. Here $z$ is the height above the surface and $z_{\mathrm{i}}$ is the height of the planetary boundary layer. For large negative values of $z / L$, local free convection applies in the surface layer (Tennekes, 1970). Above the surface layer, turbulent processes tend to scale 
with $z_{\mathrm{i}}$ and in this region $z_{\mathrm{i}}$ replaces $z$ as the appropriate length-scale.

Several recent studies (e.g. Otte and Wyngaard, 2001; Kim et al., 2003; Conzemius and Fedorovich, 2006) have investigated various aspects of entrainment which is the principal physical process that determine the evolution of a CBL (Fedorovich and Conzemius, 2008).

\subsection{Unstably stratified flows during swell}

Grachev and Fairall (2001) and Rutgersson et al. (2001) conclude from measurements that Monin-Obukhov Similarity Theory (MOST) is not applicable during swell, and present wind-wave coupling models and bulk formulae overlook the wind-following swell effect and therefore overestimate wave-induced stress and momentum input to the ocean in light winds. Nevertheless, MO scaling is used in most models over sea and the Obukhov length provides a basic relative measure of mechanical and thermal production, which we will use to diagnose stability effects for the CBL during swell. Smedman et al. $(1994,1999)$ showed that during unstable conditions the swell-induced boundary layer resembles a convectively mixed boundary layer.

Large-eddy simulations have previously been used to help in the interpretation of measurement results over sea (Edson et al., 2007; Sullivan et al., 2008), and they emphasized the importance of including information about the wave field as well as the wind field in flux parametrizations. In a series of new simulations using the LES code described in Sullivan et al. (2008), we explore effects of idealized swell waves on wind fields under a range of different stabilities. The basic structure of turbulent wind fields and momentum fluxes during wind-following swell for neutral and convective boundary layers is described. We particularly focus on the effects of stratification during swell, which have only been briefly investigated in previous work. To put these new LES investigations in context, we have investigated the neutral and convective ABL over flat terrain using five high-resolution LES runs with different stratifications.

In section 2, the LESs performed are briefly discussed and global parameters of the analyzed ABL states are presented. The main results are presented in section 3. The field measurements are described in section 3.1. A comparison between simulations and field measurements are discussed in section 3.2. In section 3.3 we continue our investigation of turbulent flows with and without swell effects to provide a more complete view of the processes present in ABLs. Special emphasize is placed on understanding the effects of convection during swell. Section 4 is a discussion of our findings, and conclusions are given in section 5 .

\section{The large-eddy simulations}

LES of ABLs influenced by swell is an attractive and complementary alternative to direct measurements. LES is well suited to study the interaction between turbulence and swell, as the swell waves can be well resolved with reasonable LES meshes.

In a new series of simulations, the $\mathrm{ABL}$ is investigated for neutral to moderately convective conditions, $-z_{\mathrm{i}} / L \leq 30$, with and without swell waves. We use a computational domain $(1200,1200,800) \mathrm{m}$ discretized using $(250,250,96)$ grid points, as reported in previous simulations (Sullivan et al., 2008). The horizontal resolution is thus high enough $(4.8,4.8) \mathrm{m}$ so that the imposed two-dimensional wave form, with wavelength $\lambda=100 \mathrm{~m}$ and wave slope $a k=0.1$, at the lower boundary is well resolved. Approximately 21 grid points per wavelength are used. Based on the linear dispersion relationship $c^{2}=g \lambda / 2 \pi$, the moving wave has a phase speed, $c=12.5 \mathrm{~m} \mathrm{~s}^{-1}$, and propagates in the $x$ direction.

A variable vertical grid spacing is employed which gives a high vertical resolution near the surface (Figure 1) with $\delta \zeta=1 \mathrm{~m}$ at the first grid point. Here $\zeta$ denotes the vertical computational coordinate. The grid aspect ratio near the surface is just within the acceptable limits for anisotropic LES grids (Scotti et al., 1993; Sullivan et al., 2008). Approximately 75 grid levels are located between the surface and the PBL inversion. A high-Reynolds-number surface drag law based on a ' $z_{0}$ ' boundary condition is applied at the lower boundary with a relatively small surface roughness value $z_{0}=0.0002 \mathrm{~m}$. In the case of simulations of swell, the $z_{0}$ value represents the drag of unresolved small-scale waves riding on the larger-scale resolved swell. The surface heat flux $Q_{*}$ and geostrophic wind forcing $\left(U_{\mathrm{g}}, V_{\mathrm{g}}\right)$ were varied between simulations and are provided in Table 1. The Coriolis parameter $f=10^{-4} \mathrm{~s}^{-1}$ was used in all runs. The initial depth of the ABL is $z_{\mathrm{i}}=400 \mathrm{~m}$ and the initial temperature profile is $\mathrm{d} \theta / \mathrm{d} z=0$ up to $z_{\mathrm{i}}$ with a strong stable inversion $\mathrm{d} \theta / \mathrm{d} z=0.01 \mathrm{~K} \mathrm{~m}^{-1}$ above $z_{\mathrm{i}}$.

The code uses pseudospectral spatial discretization in surface-following coordinates $(\xi, \eta)$ and a second-order finite-difference scheme in the vertical coordinate $\zeta$. A third-order Runge-Kutta time-stepping scheme operating with a fixed CFL number is employed. The high phase speed and small horizontal grid spacing severely limits the allowable time step, about $\delta t=0.2 \mathrm{~s}$, and the simulations require many large-eddy turnover times before reaching a quasi-steady state. Restart volumes with fully developed turbulence archived from previous solutions were used to reduce the high computational cost. In simulations with waves, the pressure Poisson equation is solved by an iterative

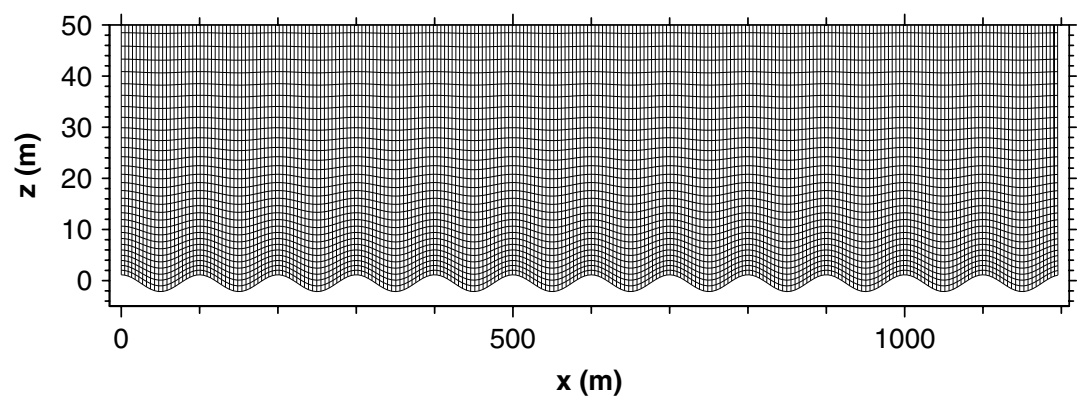

Figure 1. An $x-z$ view of the conformal computational mesh in the lowest $50 \mathrm{~m}$ of the domain, from Sullivan et al. (2004). 
Table 1. Details of the ABL states analyzed. Global parameters are shown for simulations of flat $z_{0}$ surface (Z) and wind-following swell cases (F) with neutral $(\mathrm{N})$ and convective $(\mathrm{C})$ conditions.

\begin{tabular}{|c|c|c|c|c|c|c|c|}
\hline Simulation & $z_{\mathrm{i}}(\mathrm{m})$ & $Q_{*}\left(\mathrm{Km} \mathrm{s}^{-1}\right)$ & $-z_{\mathrm{i}} / L$ & $u_{*}\left(\mathrm{~m} \mathrm{~s}^{-1}\right)$ & $U_{\mathrm{g}}\left(\mathrm{m} \mathrm{s}^{-1}\right)$ & $c_{\mathrm{p}} / U_{10}$ & $c_{\mathrm{p}} / U_{\lambda}$ \\
\hline $\mathrm{ZN1}$ & 539 & 0.0 & 0 & 0.131 & 5 & 0 & 0 \\
\hline $\mathrm{ZC} 1$ & 530 & 0.001 & 2.1 & 0.147 & 5 & 0 & 0 \\
\hline $\mathrm{ZC} 2$ & 520 & 0.005 & 8.2 & 0.159 & 5 & 0 & 0 \\
\hline ZC3 & 536 & 0.01 & 15.1 & 0.165 & 5 & 0 & 0 \\
\hline $\mathrm{ZC} 4$ & 568 & 0.02 & 28.8 & 0.170 & 5 & 0 & 0 \\
\hline FN1 & 539 & 0.0 & 0 & 0.190 & 5 & 2.42 & 2.53 \\
\hline $\mathrm{FC} 1$ & 538 & 0.001 & 1.0 & 0.189 & 5 & 2.48 & 2.48 \\
\hline FC2 & 517 & 0.005 & 4.3 & 0.196 & 5 & 2.50 & 2.51 \\
\hline FC3 & 529 & 0.01 & 8.4 & 0.198 & 5 & 2.55 & 2.53 \\
\hline FC4 & 566 & 0.02 & 17.3 & 0.201 & 5 & 2.59 & 2.55 \\
\hline FN2 & 537 & 0.0 & 0 & 0.135 & 1 & 4.28 & 6.38 \\
\hline
\end{tabular}

$z_{\mathrm{i}}$ is the boundary-layer depth, $Q_{*}$ is the average surface temperature flux, $L$ is the Obukhov length-scale,

$u_{*}$ is the surface friction velocity, $U_{\mathrm{g}}$ is the geostrophic wind speed, and

$c_{\mathrm{p}} / U_{10}$ and $c_{\mathrm{p}} / U_{\lambda}$ are the wave-age parameter defined using the mean wind speed at $10 \mathrm{~m}$ and $100 \mathrm{~m}$, respectively.

method that adds more than $50 \%$ to the computational cost compared to simulations with flat lower boundaries. We employ a subgrid-scale (SGS) model using a transport equation for SGS energy $e$. The SGS model and LES code are described in Sullivan et al. $(1994,2008)$.

All statistics shown are determined from spatial and temporal averaging of the last three hours of a simulation using archived 3D volumes stored about every second minute. For our swell wave simulations, horizontal averages $\langle\ldots\rangle$ are carried out along $\zeta=$ constant surfaces, which follows the wavy lower surface boundary and blends smoothly into a flat grid with increasing height. The resolved momentum fluxes from our swell wave simulations are based on the $W$ velocity component normal to constant $\zeta$ surfaces. In the following analysis, we will use $u, v$ and $w$ to denote the resolved field variables, and $\bar{u}, \bar{v}$ and $W$ for fluxes and variances. The contravariant flux velocity $W \rightarrow \bar{w}$ when the horizontal grid levels are effectively level (Sullivan et al., 2008) and the total vertical momentum flux in the wavefollowing mean Ekman momentum equations (Eqs 1(a,b) in Sullivan et al., 2008) is then dominated by $\langle\bar{u} W\rangle$ and $\langle\bar{v} W\rangle$ when SGS contributions are small. In visualizations of the turbulent flow, we use the resolved Cartesian coordinates $\bar{u}, \bar{v}$ and $\bar{w}$. The PBL height $z_{\mathrm{i}}$ has been determined using the vertical position of the maximum potential temperature gradient (Sullivan et al., 1998). We will qualitatively assess the success of our simulations using vertical profiles of measured low-order moments of basic flow parameters to evaluate the model for strongly swell-dominated conditions.

\section{Results}

\subsection{Measurements}

The data used to assess the overall behaviour of simulated mean flow profiles during swell is based on analysis of measurements made in the Baltic Sea within the joint US-Swedish-Finnish experiment BASE (Baltic Sea Swell Experiment) conducted at and around the MIUU (the Uppsala University Meteorology Group) tower at Östergarnsholm in the Baltic Sea in September-October 2003. Very detailed profiles of mean wind and turbulence characteristics were available up to $30 \mathrm{~m}$ and radiosoundings provide additional information up to heights well above the boundary layer. Also information about the wave state was collected including measurements of wave spectra from which the peak phase speed, $c_{\mathrm{p}}$, was calculated. The marine ABL flow was analyzed in terms of the wave age parameter $c_{\mathrm{p}} / U$, where $U$ is the mean wind speed most often defined at $10 \mathrm{~m}$ height. In addition, measurements from a flat land site, Marsta, are used.

Figure 2(a) shows profiles of measured mean wind speed from the land site, over water with growing sea conditions, and over water with swell conditions. The profiles are normalized with wind speed measured at the highest measuring height for each dataset (about $30 \mathrm{~m}$ ). The black curve shows the average mean wind profile (Högström, 1984) during neutral conditions over flat terrain showing a logarithmic height dependence typical at flat terrain sites.

The blue curve in Figure 2(a) shows the mean wind profile during convective conditions and growing sea (Högström et al., 2008), and a logarithmic height dependence is observed. Edson and Fairall (1998) and Högström et al. (2008) showed that wind profiles during growing sea can be normalized using Monin-Obukhov similarity theory. We thus recognize that Monin-Obukhov scaling would have been more appropriate for the cases with no waves and growing sea conditions (wind profiles shown in black and blue in Figure 2(a)) but we have instead adopted a scaling using the wind speed measured at about $30 \mathrm{~m}$ (see below).

The choice of $30 \mathrm{~m}$ as the normalization height is also used for swell conditions. The chosen height is about the same as the reported wavelengths $(\lambda=28,33,33,33,47 \mathrm{~m})$ for four out of five cases with swell analyzed from measurements in the Baltic Sea (Smedman et al., 2009).

The red curve in Figure 2(a) is the average wind profile for swell cases with wave age of 4.6 or higher (Smedman et al., 2009). They show a clear deviation from logarithmic height dependence. A low-level wind maximum with peak around $8 \mathrm{~m}$ is observed.

Figure 2(b) shows a vertical profile of shearing stress during swell. The red curve with negligible shearing stress corresponds to strong swell with $c_{\mathrm{p}} / U>4.5$ and the green curve with $c_{\mathrm{p}} / U \approx 1.5-1.9$ exhibits a decreasing momentum flux with height. However, there is a slight deviation compared to the growing sea cases with a tendency for exponential decay of shearing stresses with height at lower levels instead of a weak linear decay or an approximate constant-flux layer. The higher wind speed for this case is reported in Smedman et al. (2009) to have increased the 

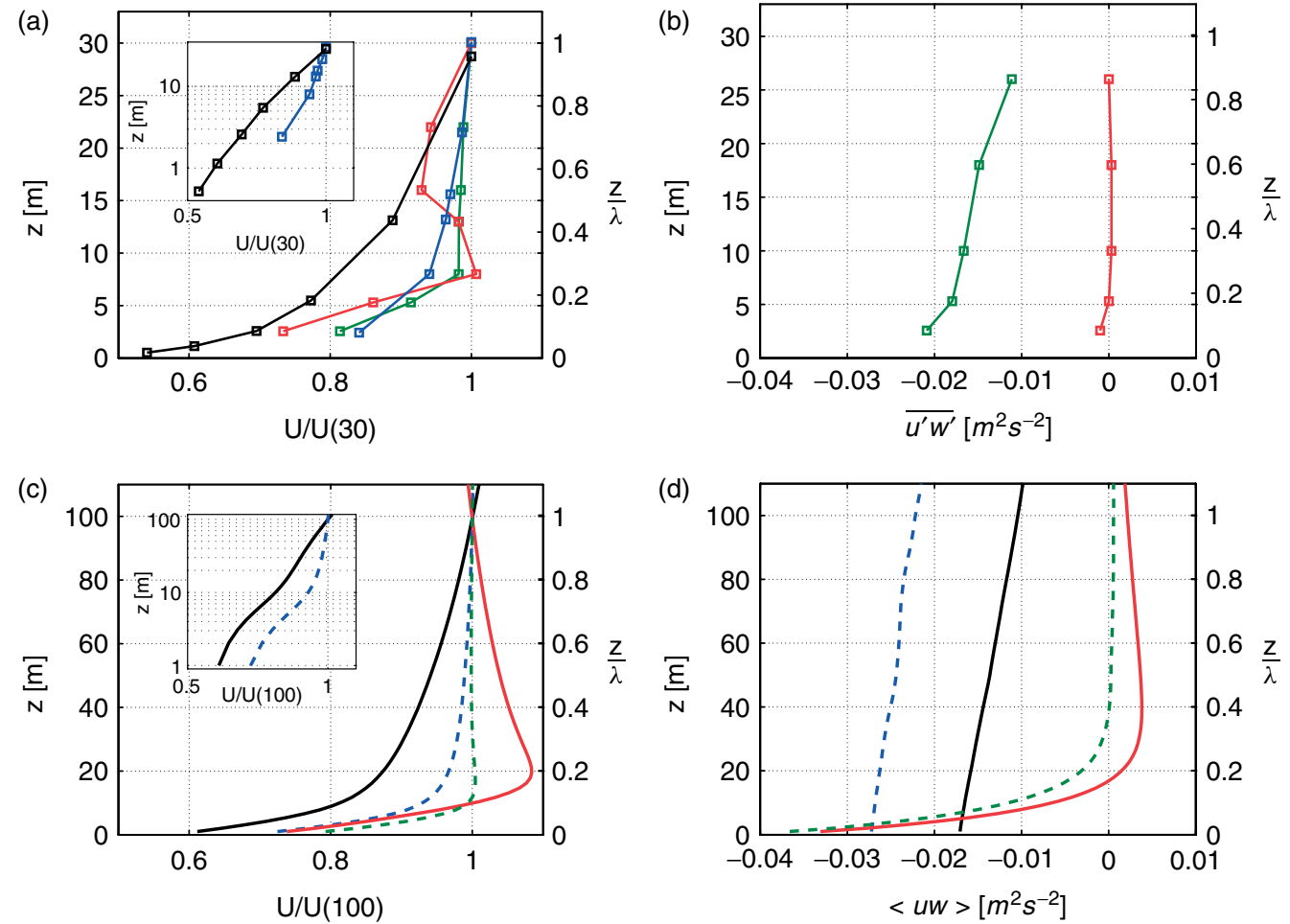

Figure 2. (a,b) Measurements and (c,d) LES predictions of vertical profiles of (a, c) mean wind speed and (b, d) mean shearing stress. Inset figures in (a) and (c) use a log vertical scale. For the measurements the cases are: black squares, no waves and neutral; blue squares, growing sea and convective conditions; red squares, swell waves during low wind speed (about $1.4 \mathrm{~m} \mathrm{~s}^{-1}$ ) near-neutral conditions; green squares, swell waves during moderate wind speed (about $4.7 \mathrm{~m} \mathrm{~s}^{-1}$ ) and convective conditions. For the LES the cases are as follows: black line, no waves and neutral (simulation ZN1); blue line, no waves and convective conditions (ZC3); red line, swell waves and neutral (FN1); green line, swell waves and convective conditions (FC3). Table 1 gives more details.

mean heat flux compared to the high-wave-age case (the red curve). The mean wind speed (green curve in Figure 2(a)) also deviates from a logarithmic height dependence and the wind speed is constant above $8 \mathrm{~m}$. In Smedman et al. (2009) it is also shown, using radiosoundings, that the constant wind speed can extend all the way up to the boundarylayer height. This suggests that the entire boundary-layer structure can be affected during swell conditions. Below $8 \mathrm{~m}$ a rapid decrease in wind speed due to surface drag causes the wind profile to obtain what is referred to as a sharp 'knee' for modest wave ages, instead of displaying a low-level wind maximum during strong swell.

\subsection{Comparisons between simulation results and measure- ments}

To qualitatively compare the simulation results to measured wind profiles, we show simulated wind speed profiles for four cases normalized with mean wind speed $U_{\lambda}$ at a height of one wavelength $(\lambda=100 \mathrm{~m})$ above the waves (Figure 2(c)). This choice of normalization with a characteristic wind speed at the height of one wavelength above the surface follows from previous analysis of direct numerical simulations of turbulent flow over swell waves (Sullivan et al., 2000), where $U_{\lambda}$ was used as characteristic wind speed.

We note when comparing Figures $2(c, d)$ with Figures $2(a, b)$ that there are several important features reproduced in our LES simulations. The simulations without swell effects (black and blue curves in Figure 2(c)) show approximately logarithmic height dependence. The neutral wind-following swell simulation shown in red reproduces a low-level wind maximum which is slightly larger than the measurements. The height of the simulated wind maximum is at $0.2 \lambda$, which agrees well with the measured value of $0.25 \lambda$. The green curve in Figure 2(c) shows the simulated wind profile for a moderately convective case, and we note that the wind maximum has been reduced and the wind speed only slightly exceeds the normalized wind speed at $100 \mathrm{~m}$ in the height range of 12 to $30 \mathrm{~m}$. A constant wind speed is seen above $30 \mathrm{~m}$ and the overall correspondence with measurements shown in green in Figure 2(a) is good.

Figure 2(d) shows the mean shearing stress, determined as the total (resolved plus SGS) vertical momentum flux, plotted as a function of height. For the neutral and moderately convective simulations without swell, the mean shearing stress has a relatively small gradient and the shear stress decreases with height, as is typical for the surface flux layer.

The swell simulation results show downward-directed momentum flux at low levels which decreases exponentially with height and for the neutral case the total momentum flux changes sign and shows upward-directed momentum flux with a maximum at about $0.35 \lambda$. For the moderately convective swell conditions, the shearing stress is close to zero above $0.35 \lambda$.

The measurements exhibit a small downward-directed momentum flux below the observed low-level wind maxima. This is probably at least partly due to the low wind speed (about $1.4 \mathrm{~m} \mathrm{~s}^{-1}$ ) reported in Smedman et al. (2009). The mean wind speed is about $4.7 \mathrm{~m} \mathrm{~s}^{-1}$ at $30 \mathrm{~m}$ for the case shown in green in Figure 2(b) and hence this higher wind speed case shows a higher level of shearing stress. 

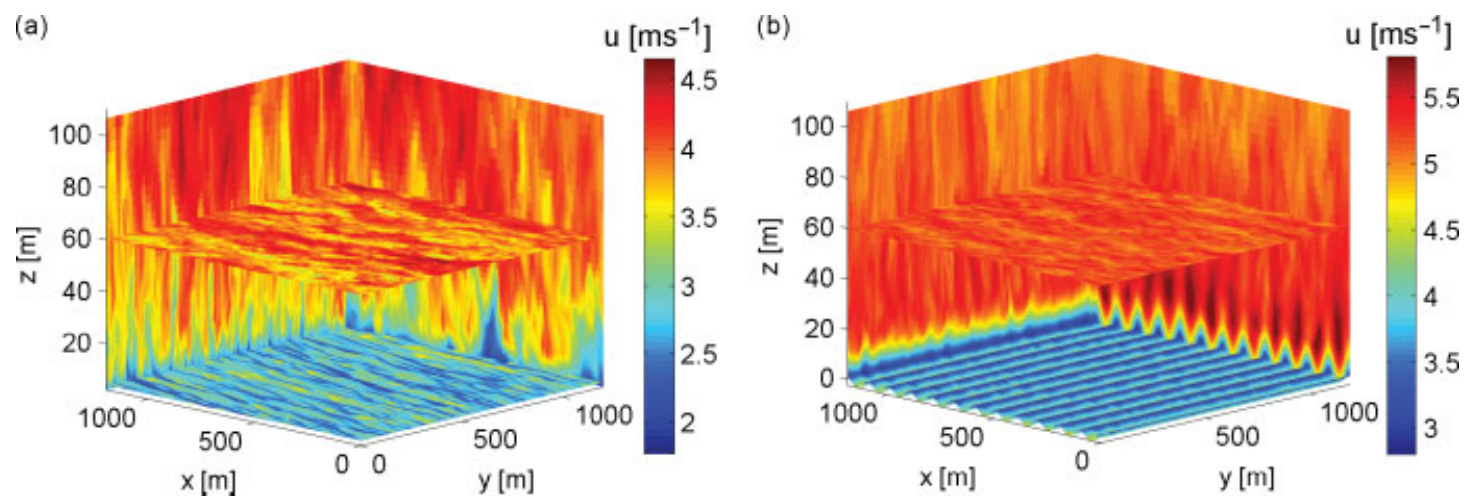

Figure 3. (a) The $\bar{u}$-component of the horizontal wind field for neutral simulation results with no waves (case ZN1) and (b) idealized swell waves (case FN1) in the lower part of the computational domain. Note that the colour scale differs between the two subfigures to capture the turbulence structure.
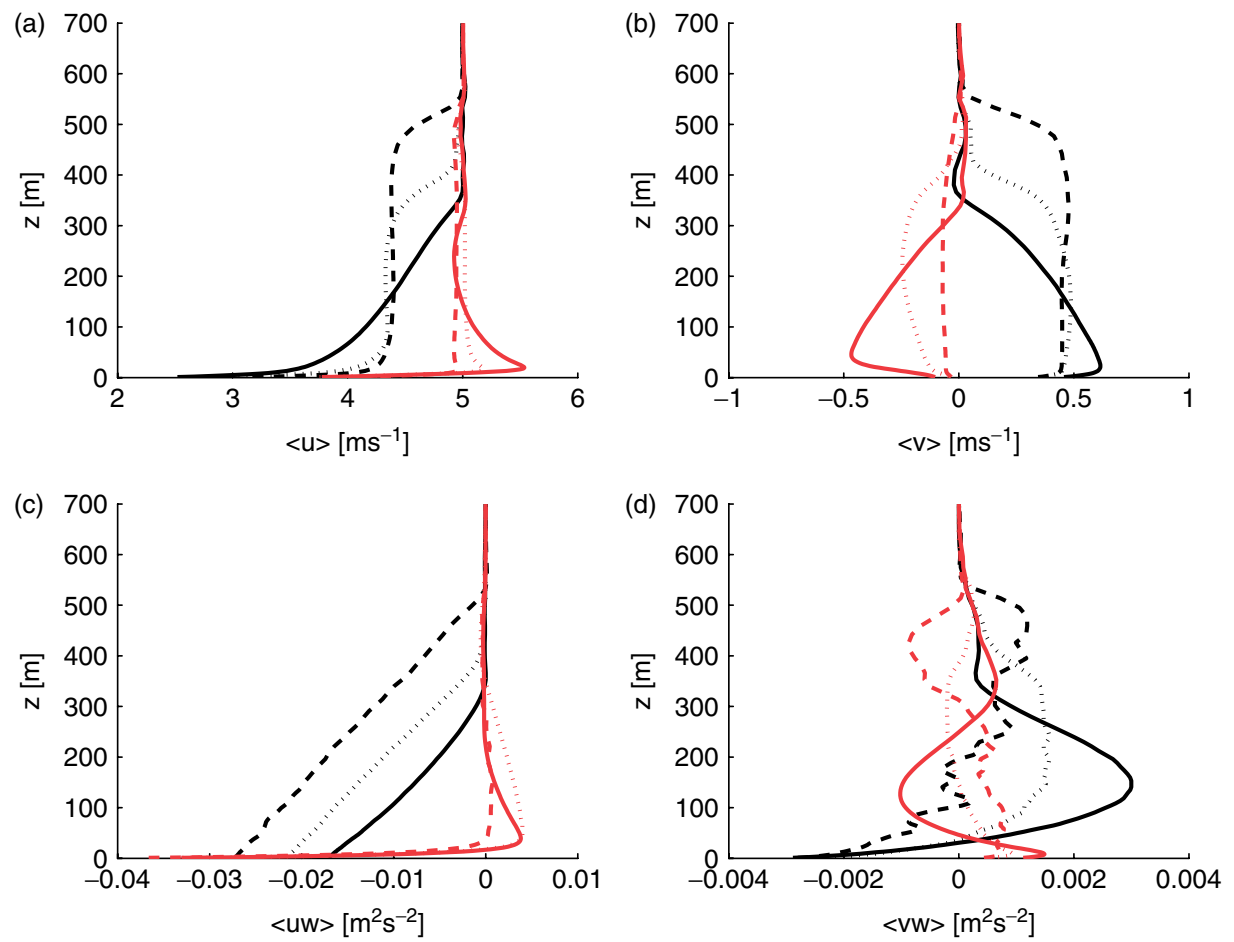

Figure 4. Vertical profiles of (a,b) the horizontal components of the mean wind, and (c, d) the total (resolved plus SGS) vertical momentum fluxes. LES results with no waves are shown in black and results including swell waves are shown in red. The stratification is varied between cases with neutral conditions (full lines; cases ZN1 and FN1), slightly convective conditions (dotted lines; cases ZC1 and FC1) and moderately convective conditions (dashed lines; cases ZC3 and FC3).

It is argued in Högström et al. (2009), based on an analysis of the turbulent kinetic energy (TKE) budget, that the combined effect of wave-induced upward momentum transport from swell and ordinary downward turbulent transport explains the observed total momentum fluxes. It is further suggested in that study that the cause of the downward turbulent transport stems from shorter (slower) waves traveling on top of the swell waves.

Below $30 \mathrm{~m}$, the fluxes in the LES during moderately convective conditions show qualitative agreement with the case with comparable wind speed (and wave age). In particular, cases with higher wind speed (and heat flux) in the measurements reveal a smooth exponential decay of the shearing stress with height, which is reproduced by LES (case F2 in Smedman et al., 2009).

Longitudinal streaks are common during growing sea conditions (Högström et al., 2008) and are a general flow feature over homogeneous land conditions and hence not a result of marine or coastal conditions. These flow features have been observed in LESs of the neutral boundary layer (Foster et al., 2006) and in high-Reynolds-number laboratory flows by Kim and Adrian (1999) and others. Figure 3(a) shows the $\bar{u}$ component of the horizontal wind field on two vertical and two horizontal slices in the lower part of the computational domain, for the neutral flat LES. The horizontal slices reveal low wind speed $u$-eddies that form 'band-like' elongation in roughly the mean wind direction. The vertical $x-z$ plane slice reveals regions of high wind speed reaching down from above causing strong local wind shear. The $y-z$ plane slice shows how these high wind speed eddies are separated by regions of lower wind speed contributing to the low wind speed streaky structures shown in the horizontal planes. Shear is crucial for the formation of streaks (e.g. Lee et al., 1990; Khanna and Brasseur, 1998), which have been shown to carry most of the vertical turbulent transport of momentum in neutrally stratified flows. 
In Figure 3(b), we illustrate the wind field during our neutral simulation of idealized swell effects by showing the $\bar{u}$ component wind on two grid levels in a wave-following coordinate system. We observe some, but weak, elongated structures at the upper horizontal slice near $60 \mathrm{~m}$. These features do not persist as we approach the surface, where instead wind speed undulations dominate the flow with high-wind-speed regions over the wave troughs and lower wind speed above the wave crests.

This is clearly illustrated in $x-z$ planes and is consistent with recently reported simultaneous measurements of seasurface displacement and wind speed from the Black Sea platform (Soloviev and Kudryavtsev, 2010). Soloviev and Kudryavtsev (2010) also found spectral peaks at the swell frequency at measuring heights ranging from 1.3 to $8 \mathrm{~m}$, although weaker for the upper levels. Uniformity of turbulence characteristics was interpreted by Högström et al. (2008) and Smedman et al. (2009) as a result of the lack of elongated low- and high-wind-speed longitudinal streaks in the surface layer during swell.

We conclude that the simulations are in many aspects consistent with field data. Differences in scale between our idealized LESs and measurements from different field campaigns are an important issue, but qualitative analogies between geophysical turbulent flows and LES fluid flows can be drawn.

\subsection{Effects of stratification on boundary-layer wind fields and momentum fluxes}

\subsubsection{Profiles of mean wind and momentum fluxes}

Simulated mean horizontal wind velocity components are shown in Figures 4(a,b) for cases with swell (red curves) and flat terrain (black curves).

Varying the surface heating results in different atmospheric stratification quantified in terms of $z_{\mathrm{i}} / L$ (Table 1 ). In Figure 4, solid curves represent neutral stratification, and dotted and dashed curves represent unstable stratification. As discussed in Sullivan et al. (2008), the wind turns to the left $\left(\langle\bar{v}\rangle\right.$ positive) as expected for flow over a flat $z_{0}$ surface. An opposite turning is observed in the presence of wind-following waves with wind turning slightly to the right $(\langle\bar{v}\rangle$ negative), as explained by an Ekman balance for momentum above waves (Sullivan et al., 2008; Hanley and Belcher, 2008) and is qualitatively similar to observations in light winds above swell reported by Grachev et al. (2003). In simplified terms, the effect can be understood by the fast moving waves imposing a positive forward thrust on the winds due to a subtle asymmetry in the pressure field relative to the underlying wave. This surface thrust from the waves is a large component of the momentum flux balance and acts counter to the usual drag induced by surface-generated turbulence and downward turbulent transport of momentum. Below the height of the low-level maximum, the winds decrease sharply to match the surface boundary conditions (Sullivan et al., 2008).

We further see how convection plays an important role for mean wind profiles with a gradual transition towards a well-mixed layer with increasing amounts of convection. In our flat simulations with surface heating, stronger wind gradients form in the surface layer close to the ground and a uniform layer with almost constant wind speed extends over a significant part of the boundary layer up to the entrainment zone. This increased mixing is caused by largescale turbulence structures formed by shear and convection. For the convective flat case, a reduced wind speed is seen in the bulk of the mixed layer with a corresponding negative shearing stress (Figures $4(\mathrm{a}, \mathrm{c})$ ).

During swell, the wind profiles exhibit several features that differ from the situation over flat terrain. Higher wind speed is maintained down to the lowest part of the boundary layer as a result of the changed momentum flux balance in the surface layer (Sullivan et al., 2008). The amount of wind turning is clearly decreased in our moderately convective case (dashed curve) with only a very slightly negatively signed $\langle\bar{v}\rangle$ profile. The reason for the decrease in magnitude of the wind maximum during more convective conditions is increased mixing from larger-scale turbulence structures (see discussion below).

For swell, the positive (upward) $u$-momentum flux present during neutral stratification increases slightly in magnitude with very small amounts of convection $\left(z_{\mathrm{i}} / L \approx\right.$ $-1)$ and persists up to about $300 \mathrm{~m}$. This was noticed already by Sullivan et al. (2004), who was speculated that surface convection transports positive vertical momentum flux, generated by swell, to the upper regions of the boundary layer. We expand on this in section 3.3.3.

\subsubsection{Convection and large-scale turbulence organization}

The large-scale organization of vertical motions into updraughts and downdraughts for our moderately convective case with swell is illustrated in Figure 5. This organization also occurs during swell when the turbulence structure of the lower part of the boundary layer is drastically changed, as depicted in Figure 3. The two vertical slices show that some of the strongest updraughts emerging from the lower levels of the boundary layer reach all the way up to the top of the boundary layer (about $530 \mathrm{~m}$ ). Isosurfaces of the vertical wind component $\left(\bar{w}=0.9 \mathrm{~m} \mathrm{~s}^{-1}\right)$ shown in red capture the organization of the strongest updraughts in elongated regions in roughly the mean wind direction. A horizontal slice close to the surface shows high-intensity swell-induced vertical wind field patterns. A partial horizontal slice in midboundary layer depicts the typically broader regions of more gentle downdraughts contrasting with the narrow regions of stronger updraughts. This is also seen in the vertical $y-z$ slice.

In CBLs over flat terrain, the vertical wind field is directly coupled to the temperature field and buoyant forces. This holds true also during wind-following swell and moderate convection where a strong correlation between updraughts (downdraughts) and regions of high (low) temperature fluctuations is found (not shown here). The governing mechanism in the large-scale organization of the turbulence, shown in Figure 5, is believed to be caused by merging of neighbouring coherent structures that originate at the surface. Moeng and Sullivan (1994) describes LES results for moderately convective conditions over flat terrain and discusses the gradual merging of streaky wall structures with increasing height. The combined action of buoyancy and strong shear is shown in Moeng and Sullivan (1994) to organize the smaller-scale near-wall streaks into larger structures. These structures are subsequently carried aloft by buoyancy and evolve into roll structures at higher $z$ levels.

Updraughts and downdraughts also strongly influence horizontal motions near the surface and at the capping 


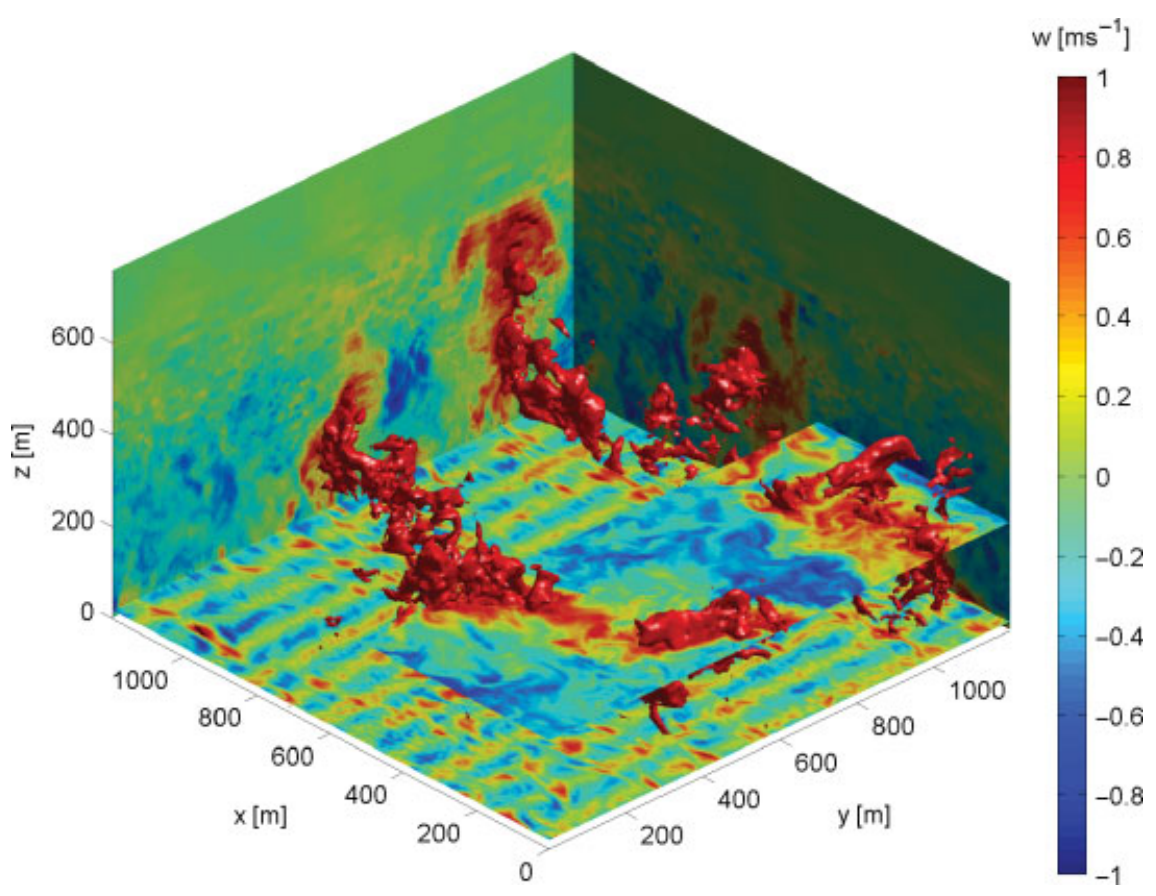

Figure 5. Large-scale organization of vertical motions into updraughts and downdraughts for a moderately convective case (FC3) with inclusion of swell wave effects. Two vertical slices show that strong updraughts emerging from the lower levels of the boundary layer reach all the way up to the boundary-layer top (about $530 \mathrm{~m}$ ). The structure of the strongest updraughts in the flow is accentuated using isosurfaces of the vertical wind component $\left(\bar{w}=0.9 \mathrm{~m} \mathrm{~s}^{-1}\right)$ shown in red. A horizontal slice at about $30 \mathrm{~m}$ reveals high-intensity swell-induced vertical wind field patterns, and a partial horizontal slice in mid-boundary layer is used to depict the typically broader regions of more gentle downdraughts contrasting with narrow regions of stronger updraughts.
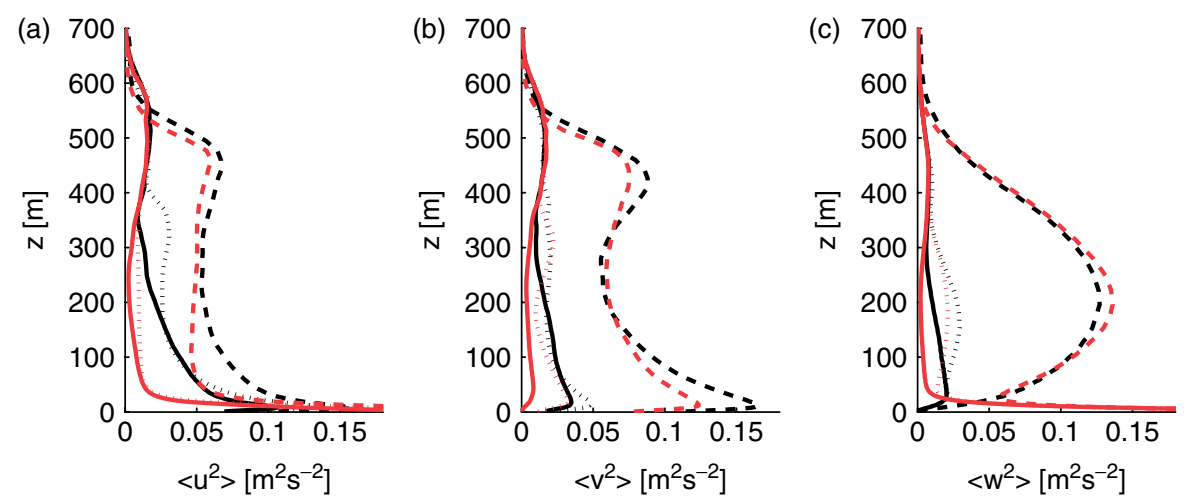

Figure 6. Vertical profiles of the resolved variance components, with the same notation as Figure 4.

inversion, where vertical motions are forced to redistribute momentum to the $u$ and $v$ components of the flow. Figure 6 shows vertical profiles of the $u, v$ and $w$ variance. Note how horizontal wind variance increases near the capping inversion; this is most clearly seen for the moderately convective case.

On the other hand, the variance of $w$ peaks in midboundary layer where a local minimum of $u$ and $v$ variance occurs. The vertical distributions of the velocity variances mainly agree with previous simulation results (e.g. Schmidt and Schumann, 1989; Moeng and Sullivan, 1994; Fedorovich et al., 2001). Near the surface, swell-induced wind speed undulations cause high-intensity wind fluctuations which enhance the variance of the $u$ and $w$ components compared to the flat case simulations. Away from the surface where wind shear is minimal, reduced or comparable variance levels are found compared to flat cases. This means a reduction of the total TKE in the bulk of the boundary layer. Sullivan et al. (2008) described a collapse of turbulence in the overall PBL due to the modification of the turbulence production mechanism in the surface layer during windfollowing swell and neutral stratification. For the moderately convective cases (FC2, FC3 and FC4), the surface convection induces turbulent motions that generate significant TKE, even in swell situations with low wind shear. In fact, in the lack of mechanical turbulence production, motions caused by buoyant turbulence production can influence the structure of the boundary layer more. Boundary layers influenced by swell are thus analogous to more convectively dominated boundary layers.

Another sign of structural similarity between swell cases and convectively dominated boundary layers is that the spectral energy in $w$ at large scales rapidly increases with height and even exceeds the spectral energy in the longitudinal wind component. This has been found in both field measurements from Östergarnsholm and from LES predictions for swell and slight convection (not shown here). 


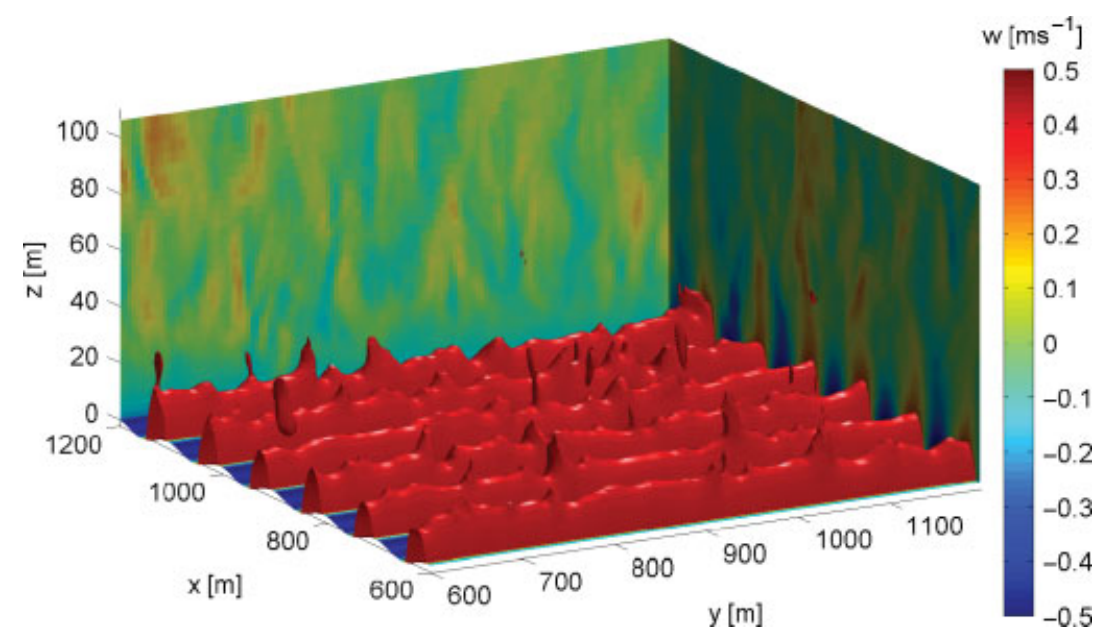

Figure 7. The vertical wind field in the lower part of the boundary layer during wind-following swell and neutral conditions (FN1) for about one quarter of the horizontal domain. Two vertical slices and one horizontal grid level in the wave-following coordinate system is used along with isosurfaces $(\bar{w}=$ $0.3 \mathrm{~m} \mathrm{~s}^{-1}$ ) to reveal the spatial structure of wave-induced updraughts and downdraughts.
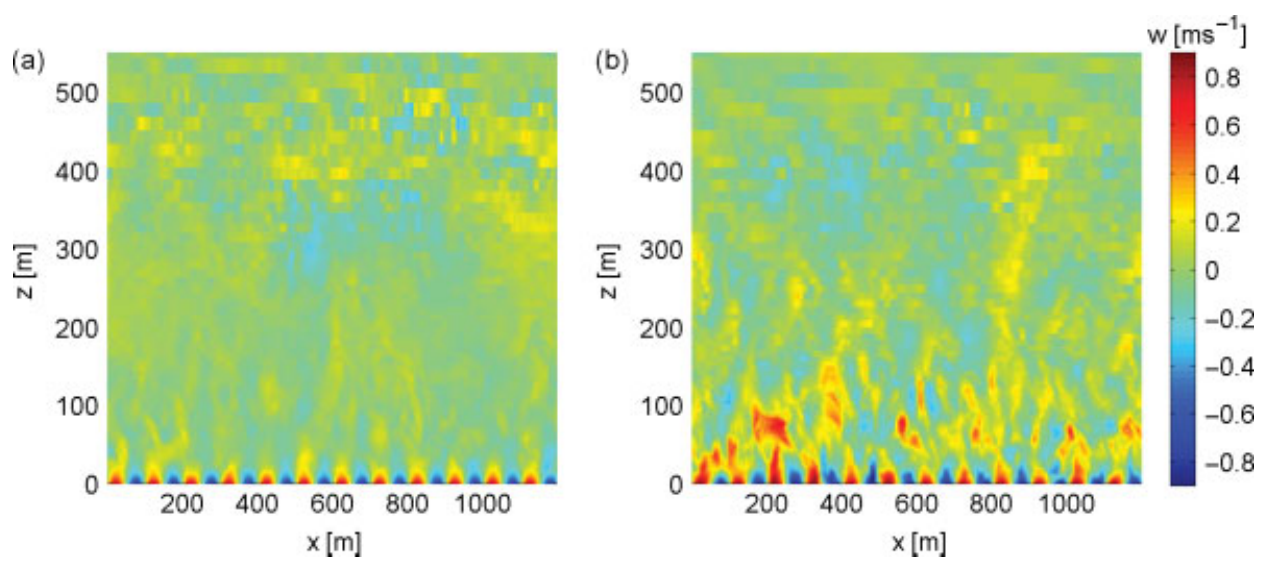

Figure 8. Vertical wind fields for neutral simulations with (a) high geostrophic wind forcing (case FN1), and (b) low geostrophic wind forcing (case FN2), resulting in different wave ages. The high wave-age case (FN2 with $U_{\mathrm{g}}=1 \mathrm{~m} \mathrm{~s}^{-1}$ ) clearly shows much stronger detached updraughts (positive $\bar{w}$ ) in the flow than the lower wave-age case (FN1 with $U_{\mathrm{g}}=5 \mathrm{~m} \mathrm{~s}^{-1}$ ).

\subsubsection{The role of detachment during swell}

In Figure 7, the vertical wind field in the lower part of the boundary layer during wind-following swell and neutral conditions is shown. We notice the formation of swellinduced updraughts (positive $\bar{w}$ ) forming downstream of the wave crests, shown by a red isosurface $\left(\bar{w}=0.3 \mathrm{~m} \mathrm{~s}^{-1}\right)$. From the vertical $x-z$ slice and the horizontal grid level, it is also seen that negative patches of vertical wind develop in the regions between the updraughts (upstream of the wave crest). The isosurface shows the formation of bulges of regions of high vertical wind speed forming at about $15 \mathrm{~m}$. Some of these bulges are seen to stretch out vertically, forming only a very thin narrow region of attachment to the directly swell wave-induced or wave-pumped updraughts below. Also seen are coherent detached positive $\bar{w}$ eddies in the flow which have formed from the interaction of the directly swell-induced wind field below and the turbulence above. These detached $\bar{w}$ eddies can, as illustrated by the vertical plane slices, form weaker large-scale structures that extend vertically.

Figures $8(\mathrm{a}, \mathrm{b})$ show the vertical wind field for two neutral cases with different geostrophic wind forcing. It is seen that detachment of $\bar{w}$ eddies strengthens with increasing wave age (reduced wind speed). It is notable how some eddies extend all the way up to the boundary-layer height (about $530 \mathrm{~m}$ ). This is not typical for neutral boundary layers over flat surfaces, but common for more convectively dominated boundary layers. For our neutral flow results with swell, this large-scale organization of vertical wind motions is found to be only weakly correlated with the very weak temperature inhomogeneities that exist in the boundary layer from entraining warmer fluid from above.

The formation of detached eddies and larger-scale organization of vertical wind fields during neutral stratification is caused by swell waves pumping turbulent wind eddies. These eddies interact with horizontal wind eddies in the flow and these turbulent structures can be enhanced by buoyancy during slightly convective conditions. This explains the increase in upward-directed transport of momentum as noted in Figure 4(c). The detached eddies with positive vertical wind speed $\left(w^{+}\right)$ correlate with regions of high horizontal wind speed to produce an upward momentum flux contribution.

\subsubsection{Conditional sampling of the vertical momentum flux}

Quadrant analysis has previously been applied to vertical momentum fluxes to expose and quantify dependencies between wave states and momentum exchange (e.g. 

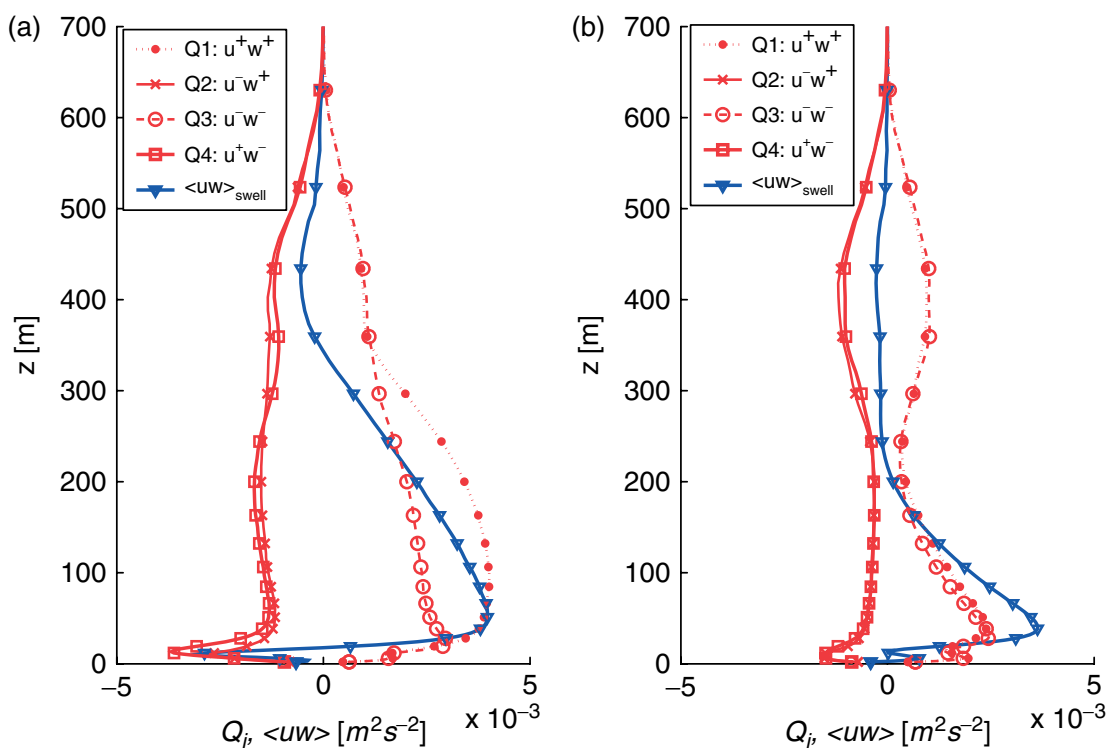

Figure 9. Vertical profiles of averaged flux contributions from the four quadrants $\left(Q_{i}\right.$; dots, crosses, circles and squares) and their sum the resolved momentum flux $(\langle u w\rangle$; triangles) for (a) slightly convective conditions (case FC1) and (b) neutral stratification (case FN1). This figure is available in colour online at wileyonlinelibrary.com/journal/qj

Smedman et al., 1999; Sullivan et al., 2008). This technique is used to analyze the turbulent $u$-momentum flux $\langle u w\rangle$ predicted from LES for the neutral and slightly unstable swell simulations. We separate the flux into four contributing terms (quadrants) according to the sign of $u$ and $w$ the fluctuating velocity components, viz. $\left[u^{+} w^{+}, u^{-} w^{+}, u^{-} w^{-}, u^{+} w^{-}\right]$. The quadrant analysis is extended by calculating the spatial area covered by the fluxes for each quadrant to verify the importance of the detachment mechanism, which we argue strengthens the upward-directed momentum flux during slightly unstable conditions.

Figure 9 shows vertical profiles of the averaged flux contributions and their sum which is the resolved momentum flux for slightly convective (Figure 9(a)) and neutral (Figure 9(b)) conditions. The total flux shows, as discussed in section 3.2, a positive maximum around $0.35 \lambda$, which is noticeably enhanced for the slightly convective case above this level, with positive flux up to $300 \mathrm{~m}$ instead of around $200 \mathrm{~m}$ for neutral conditions. This enhancement occurs by detached coherent positive $w$ eddies $\left(w^{+}\right)$which are correlated with positive $u$ eddies $\left(u^{+}\right)$, inducing an increase in the relative strength of averaged positive vertical momentum flux from the first quadrant $\left(u^{+} w^{+}\right)$compared with the other quadrants. This is indicated by the dotted line in Figure 9(a) showing enhanced relative strength of $u^{+} w^{+}$ fluxes in the height range from 35 to $350 \mathrm{~m}$.

Figure 10(a) compares the average fluxes at a nominal height of $100 \mathrm{~m}$, using the different simulations described in Table 1 , as a function of $z_{\mathrm{i}} / L$. Case FN2 was excluded due to different geostrophic wind forcing. Also shown are markers (dots, crosses, circles and squares) for the different flux contributions $\left(Q_{i}\right)$ for the swell cases (which sum to the net flux shown as triangles). All four flux terms become larger with increasingly unstable stratification; an almost linear dependence on $z_{\mathrm{i}} / L$ is shown. If the sum of the upward directed momentum flux terms $\left(u^{+} w^{+}\right.$and $\left.u^{-} w^{-}\right)$is larger (smaller) than the sum of the downward directed flux terms $\left(u^{+} w^{-}\right.$and $\left.u^{-} w^{+}\right)$a net upward (downward) flux occurs.
For moderately convective conditions, positive and negative fluxes stemming from high horizontal wind speed regions $\left(u^{+} w^{+}\right.$and $\left.u^{+} w^{-}\right)$roughly balance, and the same applies for positive and negative flux contributions from regions with lower than average horizontal wind speed $\left(u^{-} w^{-}\right.$and $\left.u^{-} w^{+}\right)$. This explains why the total flux is only marginally different from net zero within the mixed layer.

For near-neutral conditions, the net flux shown as triangles is positive (directed upwards) and enhanced for slightly convective conditions in comparison to neutral flow. In Figure 10(b), the flux contributions are normalized by the sum of their magnitudes $\left(Q_{i} / \sum\left|Q_{i}\right|\right)$ which allows us to determine the relative size of the four flux terms for each case. We notice that, for slightly convective conditions, the largest term results from updraughts correlating with regions of high horizontal wind speed $\left(u^{+} w^{+}\right.$shown as dotted line).

Figure 10(c) shows the spatial area (\%) covered by contributions from each of the different quadrants at $100 \mathrm{~m}$. We notice that the area covered by updraughts correlating with high horizontal wind speed $\left(u^{+} w^{+}\right.$shown as dotted line) is becoming smaller with increasingly convective conditions. Thus, the increase of the $u^{+} w^{+}$flux term in relation to the other terms during slightly convective conditions is not explained by an increase in the area covered by such fluxes. Instead the interpretation is that $u^{+} w^{+}$fluxes arise from strongly coherent eddies covering a small part of the total area.

The mechanism for transport of momentum to the upper levels of the ABL in the presence of swell can thus be explained by the correlation and interaction between vertical and horizontal wind eddies. Some of the strong $w$ eddies in the flow at heights of increased average $u^{+} w^{+}$flux (between 35 and $350 \mathrm{~m}$ ) are detached from the underlying swellinduced wind field (indicated by Figures 7 and 8). As previously discussed, Figure 3(b) shows a coupling between the horizontal wind and surface waves for wind-following swell with a coherent pattern of accelerated wind in the region above each wave trough. These strong coherent $u$ eddies also extend in weaker form with height and their 

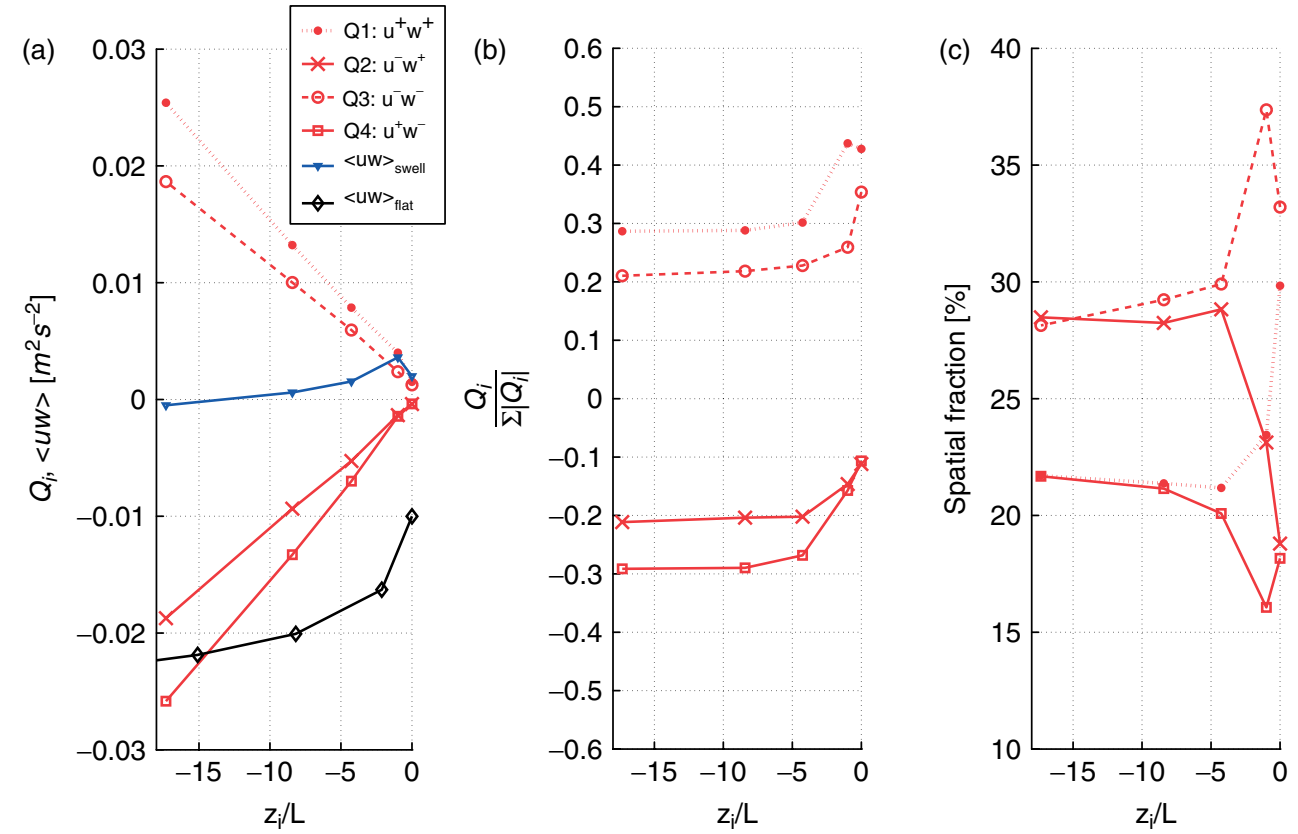

Figure 10. (a) Averaged flux contributions from the four quadrants ( $Q_{i}$; dots, crosses, circles and squares) and resolved momentum flux at a nominal height of $100 \mathrm{~m}$ above the surface, for swell waves (triangles) and for no waves (diamonds), as a function of $z_{\mathrm{i}} / L$. In (b), the flux contributions have been normalized by the sum of their magnitudes. (c) shows the areal coverage by each flux contribution as a function of $z_{\mathrm{i}} / L$. Table 1 gives additional information about the several simulations used in this composite plot. This figure is available in colour online at wileyonlinelibrary.com/journal/qj

correlation with $w$ eddies leads to a significant amount of upward-directed vertical momentum flux during nearneutral conditions.

\subsubsection{Implication for turbulence length-scales}

The turbulence structure in the presence of swell is found to increase the vertical mixing during near-neutral conditions due to the presence of wave-induced eddies in the flow. The horizontal scales of vertical velocity are characterized by the integral scales (Khanna and Brasseur, 1998)

$$
l_{33}^{\gamma}(z)=\int_{0}^{\infty} \frac{R_{33}\left(r_{\gamma}, z\right)}{R_{33}(0, z)} \mathrm{d} r_{\gamma},
$$

where

$$
R_{33}\left(r_{\gamma}, z\right)=\overline{u_{3}\left(x_{\gamma}\right) u_{3}\left(x_{\gamma}+r_{\gamma}\right)}=\overline{w\left(x_{\gamma}\right) w\left(x_{\gamma}+r_{\gamma}\right)} .
$$

Here $r_{\gamma}$ is a two-point horizontal separation vector and the ensemble average is replaced by area averaging on $x_{\gamma}$ over horizontal planes, in our case along wave-following coordinates.

Figure 11 shows the integral length-scales for $\bar{w}$ as defined by Eq. (1) for neutral stratification (a) in the direction of swell wave propagation and (b) perpendicular to this direction. Near the surface, the integral length-scale of $w$ is influenced by our idealized boundary condition implying a very large length-scale perpendicular to the wave direction (triangles in Figure 11(b)); the swell wave induces coherent updraughts and downdraughts depending on the phase of the wave. It is notable how the length-scale in this $(y)$ direction is greatly enhanced compared with the case of flat terrain (diamonds) also in mid-boundary layer. This is interpreted as a consequence of the organization and mixing by detached eddies from below. To a lesser extent, the increased mixing in mid-boundary layer in the presence of swell waves also leads to a larger integral length-scale in the direction of swell propagation (triangles in Figure 11(a)), which roughly coincides with the mean wind direction for this case of wind-following swell. Near the surface, the swell-induced updraughts and downdraughts replace the longitudinal streaks (Figures 3 and 5) and reduces the integral length-scales in the direction of the propagating swell (Figure 11(a)).

In convective conditions, the length-scales in the uniformly mixed layer are dominated by large-scale turbulence organization (Figure 5) and the influence on vertical mixing from the inclusion of swell waves is considered less important in relation to the mixing caused by buoyancy-induced motions. However, some modification to the length-scales during convective conditions (not shown here) is a consequence of the waves, with increased lengthscale in the direction perpendicular to the swell, but with a reduction of the streamwise length-scale. The elongated streaky structures in the mean wind direction are slightly disrupted by the wave-induced motions.

\section{Discussion}

A comparison of mean wind profiles and vertical momentum fluxes from measurements and LES has been performed, and good qualitative agreement between wind profiles from field campaigns and LES is reached when scaled with the wind speed at a height of one wavelength. However, the choice of height for a normalization velocity is rather insensitive as long as it is a height above the 'knee' (or wind maximum) in the wind profile. The wind speed varies little with height above this 'knee' for our simulation results, which is verified from measurements using radiosoundings (Smedman et al., 2009). There is no scaling in the literature that is accepted to be universally valid during swell conditions, likely because of the complicated character of multi-component wave fields and their interaction with local wind. In the light of this, 

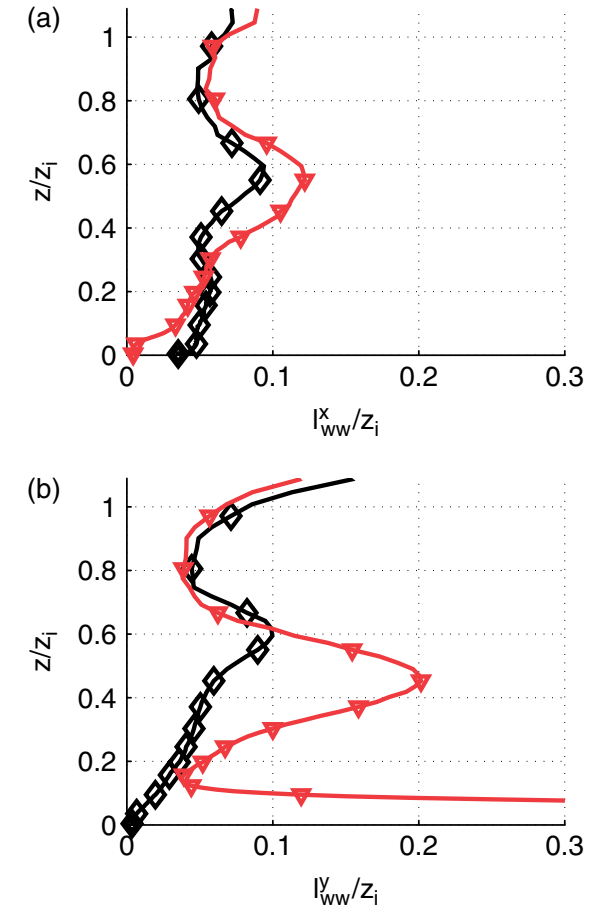

Figure 11. Integral length-scales of $w$ for neutral stratification as defined by Eq. (1) normalized with $z_{\mathrm{i}}$. The swell wave case (FN1; line with triangles) and flat case (ZN1; line with diamonds) are shown for (a) the direction of the swell wave propagation (roughly coinciding with the mean wind direction) and (b) perpendicular to this direction. This figure is available in colour online at wileyonlinelibrary.com/journal/qj

the suggested scaling that results in the wind maximum at roughly the same normalized height in both LES simulations and measurements is likely valid only for very pure swell with waves from one direction, such as those that persisted during the BASE campaign (Smedman et al., 2009). The height of the 'knee' in the wind profile is likely dependent on the contribution of drag from short waves and hence the energy in the high-frequency part of the measured wave spectrum. Following the discussion in Högström et al. (2009), these short waves, which in the LES are represented by a $z_{0}$ parametrization, have a significant influence near the surface but a more limited effect higher up.

Successful LES of neutral flow over a flat surface can be more difficult than simulations of flow over topography because of the lack of major forcing mechanisms (Ludwig et al., 2008). Sullivan et al. (2008) state that it is expected that the dependence on the SGS closure is less in LES of flow over idealized swell waves than in simulations of neutral flow over flat surfaces, because the surface form (pressure) stress is resolved. Hence there is less reliance on the SGS model to support surface fluxes in the presence of resolved wavy surfaces. This speculation is supported by direct numerical simulations (Sullivan et al., 2000).

The local structure of the primary energy-containing motions in the ABL with and without swell has been analyzed using a combination of statistics and $3 \mathrm{D}$ visualizations using LES data. Large-scale organization of turbulence in the CBL during swell (Figure 5) has been shown to involve similar structures to those discussed by Moeng and Sullivan (1994) and Khanna and Brasseur (1998) over flat terrain, and many other studies of the dynamics of sheared CBLs (Fedorovich and Conzemius, 2008). The merging of plumes into the mean wind direction and strengthening of streaky elongated flow features for more convectively stratified atmospheric states also persists when the lower-level dynamics are drastically changed by swell. However, a striking result is that the effect of the changed momentum flux balance in the lower part of the boundary layer persists even for a moderately convective flow regime where turbulence levels are significantly increased. A boundary layer with reduced wind drag which maintains high horizontal wind speed (Figure 4) within the bulk of the boundary layer suggests that a strong swell wave can affect the evolution of winds and fluxes within the entire boundary layer.

By examining the vertical momentum flux using a conditional sampling technique, we show how the high wind speeds are maintained by a near-net-zero momentum balance (Figure 10). Both downward and upward momentum flux contributions increase for increasingly unstable conditions, however by roughly the same amount, so that they nearly cancel within the uniformly mixed layer. In the free convection limit, the total momentum flux also remains close to zero because of a balance between upwardand downward-directed flux, although significant large-scale organization of the flow into Rayleigh-Benard cell patterns forms in this buoyancy-driven flow regime (Khanna and Brasseur, 1998). A similar balance with net zero momentum flux over the bulk of the boundary layer is reached for our moderately convective swell simulations, but the large-scale turbulence organization is more similar to what is expected for boundary layers influenced by moderate convection (Figure 5).

For neutral and slightly convective conditions, upward momentum flux is observed to be dominated by updraughts correlating with regions of high horizontal wind speed. Part of this upward flux originates from coherent eddies that extend vertically and detach from the swell-induced or wave-pumped motions near the surface. This process strengthens with increasing wave age, resulting in higher wave-induced flux and a stronger wind maximum relative to the geostrophic wind. The detachment process is also found to strengthen as a result of slight convection, likely because temperature fluctuations increase the coherence of pre-existing turbulent motions already present during neutral conditions.

Similarities between boundary layers influenced by swell waves and convectively dominated boundary layers have been discussed in previous work (e.g. Smedman et al., 1994, 1999; Rutgersson et al., 2001) with the general and very reasonable argument that this occurs because the relative importance of $u_{*}$ decreases in both cases. A convectively dominated boundary layer exists when buoyancy production of turbulence exceeds mechanical turbulence production and hence the boundary layer is driven by the surface heat flux. In swell-dominated situations, a wave-induced stress component changes the momentum flux balance near the surface, with reduced drag as a result. This implies that even small heat fluxes can play a significant role during swell. The aforementioned role of detachment during wind-following swell, in combination with a small amount of convection, have also been shown to potentially play a large role for upward transport of momentum in marine boundary layers.

Cuxart et al. (2000) suggested that integral length-scales could be useful for investigating mixing-length formulations in turbulence schemes in mesoscale models. A similar mixing-length formulation (Lenderink and de Rooy, 2000; Lenderink and Holtslag, 2004) is used in the Swedish 
Meteorological and Hydrological Institute's Rossby Centre atmospheric regional climate model, which is used in developing a coupled wave-atmosphere system (Rutgersson et al., 2010). The close resemblance between the lengthscale of the energy-containing eddies from LES and of a parametrized mixing length for convective conditions over flat terrain, except for a proportionality factor, has been shown in (Cuxart et al., 2000). The integral length-scales for our neutral swell simulations are in agreement with previous results found for more convective conditions over flat terrain, except near the surface. This supports our view that boundary layers influenced by swell have similarities to CBLs.

One particularly interesting aspect of the simulated CBLs with swell in this study is the reduced elevated shear which could have a significant impact on entrainment processes (Conzemius and Fedorovich, 2006). Sahlée et al. (2009) have shown, using the European Centre for Medium-range Weather Forecasts ERA-40 dataset, that the mean boundarylayer height over the oceans near the Equator is relatively shallow (less than $800 \mathrm{~m}$ ), due to low mean wind speeds. These regions have been shown by Semedo et al. (2011) using the ERA-40 wave reanalysis to be swell dominated $\left(c_{\mathrm{p}} / U_{10}>1.2\right)$ close to $100 \%$ of the time. Also most areas in the Tropics were shown in Sahlee et al. (2009) to be dominated by convective conditions with $z_{\mathrm{i}} / L$ in the range 0 to -20 . The influence of organized turbulent structures such as horizontal convective rolls on the horizontal distribution of shear in the entrainment zone is a question that needs to be further explored (Conzemius and Fedorovich, 2006). Swell could possibly play an indirect role for the entrainment dynamics, which is described by Kim et al. (2003) to depend on both the friction velocity and convective velocity that determine the convective roll structure within the boundary layer, as well as velocity jumps across the inversion layer.

\section{Summary and conclusions}

In this study, a set of new LES runs has been used to analyze the combined impact of swell and convection on boundary-layer winds and momentum fluxes. The following conclusions were reached:

1. Good qualitative agreement between LES and field measurements was found for strongly swelldominated situations when vertical profiles of mean wind and fluxes were compared.

2. Wave-induced motions in the presence of strong swell significantly change the near-surface wind field and momentum flux balance compared with flat boundary layers with reduced drag as its primary effect. The wave-induced or wave-pumped motions are similar to those reported in Soloviev and Kudryavtsev (2010). These motions modulate the longitudinal streaks found in typical ABLs.

3. The reduced drag during swell and upward momentum flux from the waves to the atmosphere is predicted by LES to maintain higher wind speeds in the ABL during swell. Also during neutral conditions, a lowlevel wind maximum observed in measurements is qualitatively reproduced. Convection is found to play an important role for mean wind profiles. A gradual transition towards a well-mixed layer with increasing amounts of convection is explained by larger-scale eddies effectively mixing the horizontal momentum and thereby reducing the wind maximum.

4. LES predicts that upward momentum flux is strongest during neutral and slightly convective conditions in situations with similar external factors (geostrophic wind speed $U_{\mathrm{g}}$ and inversion strength $\mathrm{d} \theta / \mathrm{d} z$ ). By a conditional sampling technique, it is concluded that most of the upward flux originates from updraughts correlated with high horizontal wind speed motions. This analysis in combination with $3 \mathrm{D}$ visualizations also reveals how the upward flux can be interpreted in terms of detached eddies that originate from swellinduced motions near the surface.

5. The detachment of wave-induced wind eddies are found to be highly dependent on wave age. This mechanism qualitatively explains how an increase of wave age (reduction of wind speed) can cause stronger vertical wind fluctuations in the boundary layer and a stronger wind maximum in relation to the geostrophic wind speed.

6. Integral length-scales for vertical velocity are increased in mid-boundary layer in the presence of windfollowing swell during neutral conditions. This is interpreted as a consequence of wave-induced vertical wind motions that cause increased mixing compared with neutral boundary-layer flow over flat terrain. The resulting length-scales are found to vary similar to how mixing lengths are prescribed for the CBL in larger-scale atmospheric models.

7. The detachment mechanism is also found to be stronger during slightly convective conditions because the coherence of the turbulence structure present during neutral conditions strengthens. This causes an increase of the upward momentum flux during slightly convective conditions compared with neutral conditions.

8. For moderately convective conditions, high wind speeds are maintained by a near-net-zero momentum balance. Downward and upward momentum flux contributions both increase for increasingly unstable conditions but by roughly the same amount such that they nearly cancel within the uniformly mixed layer. This emphasizes that the impact of swell can be strong with reduced drag as its primary effect, even in situations where turbulence levels are significantly increased due to buoyant turbulence production.

\section{Acknowledgements}

The computations were performed on resources provided by SNIC through Uppsala Multidisciplinary Center for Advanced Computational Science (UPPMAX) under project p2008008, Impact of waves on turbulence. The authors would like to thank members of the MIUU staff and AWEP group for discussions regarding this work.

\section{References}

Antonia R, Chambers A. 1980. Wave-induced disturbances in the marine surface layer. J. Phys. Oceanogr. 10: 611-622.

Conzemius R, Fedorovich E. 2006. Dynamics of sheared convective boundary layer entrainment. Part I: Methodological background and large-eddy simulations. J. Atmos. Sci. 63: $1151-1178$. 
Cuxart J, Bougeault P, Redelsperger J-L. 2000. A turbulence scheme allowing for mesoscale and large-eddy simulations. Q. J. R. Meteorol. Soc. 126: $1-30$.

Davidson K, Frank A. 1973. Wave-related fluctuations in the airflow above natural waves. J. Phys. Oceanogr. 3: 102-119.

Donelan M. 1990. Air-sea interaction. In The Sea, Ocean Engineering Science 9. Wiley Interscience: New York.

Edson J, Fairall C. 1998. Similarity relationships in the marine atmospheric surface layer for terms in the TKE and scalar variance budgets. J. Atmos. Sci. 55: 2311-2328.

Edson J, Crawford T, Crescenti J, Farrar T, Frew N, Gerbi G Plueddemann A, Trowbridge J, Weller R, Williams AJ III, Helmis C, Hristov T, Shen L, Khelif D, Jessup A, Jonsson H, Li M, Mahrt LA, Skyllingstad E, Vickers D, McGillis W, Zappa C, Stanton T, Wang Q Sullivan P, Sun J, Wang S, Wilkin J, Yue DKP. 2007. The coupled boundary layers and air-sea transfer experiment in low winds. Bull. Amer. Meteorol. Soc. 88: 341-356.

Fedorovich E, Conzemius R. 2008. Effects of wind shear on the atmospheric convective boundary layer structure and evolution. Acta Geophysica 56: 114-141.

Fedorovich E, Nieuwstadt F, Kaiser R. 2001. Numerical and laboratory study of a horizontally evolving convective boundary layer. Part 1 : Transition regimes and development of the mixed layer. J. Atmos. Sci. 58: $70-86$.

Foster R, Vianey F, Drobinski P, Carlotti P. 2006. Near-surface coheren structures and the vertical momentum flux in a large-eddy simulation of the neutrally-stratified boundary layer. Boundary-Layer Meteorol. 120: 229-255

Gent P, Taylor P. 1976. A numerical model of the air flow above water waves. J. Fluid. Mech. 77: 105-128.

Grachev A, Fairall C. 2001. Upward momentum transfer in the marine boundary layer. J. Phys. Oceanogr. 31: 1698-1711.

Grachev A, Fairall C, Hare J, Edson J, Miller S. 2003. Wind stress vector over ocean. J. Phys. Oceanogr. 33: 2408-2429.

Hanley K, Belcher S. 2008. Wave-driven wind jets in the atmospheric boundary layer. J. Atmos. Sci. 65: 2646-2660.

Hanley K, Belcher S, Sullivan P. 2010. A global climatology of wind-wave interaction. J. Phys. Oceanogr. 40: 1263-1282.

Harris D. 1966. The wave-driven wind. J. Atmos. Sci. 23: 688-693.

Högström U. 1984. Von Kármán's constant in atmospheric boundarylayer flow: Re-evaluated. J. Atmos. Sci. 42: 263-270.

Högström U, Sahlée E, Drennan W, Kahma K, Smedman AS, Johansson C, Pettersson H, Rutgersson A, Tuomi L, Zhang F Johansson M. 2008. Momentum fluxes and wind gradients in the marine boundary layer - A multi-platform study. Boreal Env. Res. 13 475-502.

Högström U, Smedman A-S, Sahlée E, Drennan W, Kahma K, Pettersson H, Zhang F. 2009. The atmospheric boundary layer during swell: A field study and interpretation of the turbulent kinetic energy budget for high wave ages. J. Atmos. Sci. 66: 2764-2779.

Hristov T, Friehe C, Miller S. 1998. Wave-coherent fields in air flow over ocean waves: Identification of cooperative behaviour buried in turbulence. Phys. Rev. Lett. 81: 5245-5248.

Hristov T, Miller S, Friehe C. 2003. Dynamical coupling of wind and ocean waves through wave-induced air flow. Nature 422 55-58.

Janssen PAEM. 1989. Wave-induced stress and the drag of air flow over sea waves. J. Phys. Oceanogr. 19: 745-754.

Khanna S, Brasseur J. 1998. Three-dimensional buoyancy- and shearinduced local structure of the atmospheric boundary layer. J. Atmos. Sci. 55: 710-743

Kim K, Adrian R. 1999. Very-large-scale motion in the outer layer. Phys. Fluids 11: 417-422.

Kim SW, Park SU, Moeng C-H. 2003. Entrainment processes in the convective boundary layer with varying wind shear. Boundary-Layer Meteorol. 108: 221-245.

Kitaigorodskii S. 1973. The Physics of Air-Sea Interaction. Israel Program for Scientific Translations: Jerusalem.

Lai R, Shemdin O. 1971. Laboratory investigation of air turbulence above simple water waves. J. Geophys. Res. 76: 7334-7350.

Lee M, Kim J, Moin P. 1990. Structure of turbulence at high shear rate. J. Fluid. Mech. 216: 561-583.
Lenderink G, de Rooy W. 2000. 'A robust mixing-length formulation for a TKE-l turbulence scheme'. HIRLAM Newsletter 36: 25-29.

Lenderink G, Holtslag A. 2004. An updated length-scale formulation for turbulent mixing in clear and cloudy boundary layers. Q. J. R. Meteorol. Soc. 130: 3405-3427.

Ludwig F, Chow F, Street R. 2008. 'The need for caution when interpreting velocity field structures predicted by LES'. In: Proceedings of 18th AMS Symposium on Boundary Layers and Turbulence, 9-13 June, Stockholm, Sweden.

Makin V, Mastenbroek C. 1996. Impact of waves on air-sea exchange of sensible heat and momentum. Boundary-Layer Meteorol. 79: 279-300.

Makova V. 1975. Features of the dynamics of turbulence in the marine atmospheric surface layer at various stages in the development of waves. Atmos. Ocean. Phys. 11: 177-182.

Miles J. 1957. On the generation of surface waves by shear flows. J. Fluid. Mech. 3: 185-204.

Moeng C-H, Sullivan P. 1994. A comparison of shear- and buoyancydriven planetary boundary-layer flows. J. Atmos. Sci. 51: 999-1022.

Otte M, Wyngaard J. 2001. Stably stratified interfacial-layer turbulence from large eddy simulation. J. Atmos. Sci. 58: 3424-3442.

Phillips O. 1957. On the generation of waves by turbulent wind. J. Fluid. Mech. 2: 417-445.

Rutgersson A, Sullivan P. 2005. The effect of idealized water waves on the turbulence structure and kinetic energy budgets in the overlying airflow. Dyn. Atmos. Oceans 38: 147-171.

Rutgersson A, Saetra Ø, Semedo A, Carlsson B, Kumar R. 2010. Impact of surface waves in a regional climate model. Meteorol. Z. 19: $247-257$.

Rutgersson A, Smedman A-S, Högström U. 2001. Use of conventional stability parameters during swell. J. Geophys. Res. 106: 27117-27134.

Sahlée E, Smedman A-S, Högström U. 2009. Influence of the boundarylayer height on the global air-sea surface fluxes. Clim. Dyn. 33: 33-44.

Schmidt H, Schumann U. 1989. Coherent structure of the convective boundary layer derived from large-eddy simulations. J. Fluid. Mech. 200: $511-562$.

Scotti A, Meneveau C, Lilly D. 1993. Generalized Smagorinsky model for anisotropic grids. Phys. Fluids A 5: 2306-2308.

Semedo A, Suseli K, Rutgersson A, Sterl A. 2011. A global view on the wind sea and swell climate and variability from ERA-40. J. Climate 24: $1461-1479$.

Smedman A-S, Högström U, Berggström H, Rutgersson A, Kahma K, Pettersson H. 1999. A case study of air-sea interaction during swell conditions. J. Geophys. Res. 104: 25833-25851.

Smedman A-S, Högström U, Sahlée E, Drennan W, Kahma K, Pettersson H, Zhang F. 2009. Observational study of marine atmospheric boundary-layer characteristics during swell. J. Atmos. Sci. 66: 2747-2763.

Smedman A-S, Tjernström M, Högström U. 1994. The near-neutral marine atmospheric boundary layer with no surface shearing stress: A case study. J. Atmos. Sci. 51: 3399-3411.

Soloviev Y, Kudryavtsev V. 2010. Wind-speed undulations over swell: Field experiment and interpretation. Boundary-Layer Meteorol. 136: 341-363.

Sullivan P, McWilliams J. 2010. Dynamics of winds and currents coupled to surface waves. Annu. Rev. Fluid Mech. 49: 19-42.

Sullivan P, Edson J, Hristov T, McWilliams J. 2008. Large-eddy simulations and observations of atmospheric marine boundary layers above non-equilibrium surface waves. J. Atmos. Sci. 65: 1225-1245.

Sullivan P, Edson J, McWilliams J, Moeng C-H. 2004. 'Large-eddy simulations and observations of wave-driven boundary layers'. In: Proceedings of 16th AMS Symposium on Boundary Layers and Turbulence, 9-13 August, Portland, OR.

Sullivan P, McWilliams J, Moeng C-H. 1994. A subgrid-scale model for large-eddy simulation of planetary boundary-layer flows. BoundaryLayer Meteorol. 71: 247-276.

Sullivan P, McWilliams J, Moeng C-H. 2000. Simulation of turbulent flow over idealized water waves. J. Fluid. Mech. 404: 47-85.

Sullivan P, Moeng C-H, Stevens B, Lenschow D, Mayor S. 1998. Structure of the entrainment zone capping the convective atmospheric boundary layer. J. Atmos. Sci. 55: 3042-3064.

Tennekes H. 1970. Free convection in the turbulent Ekman layer of the atmosphere. Phys. Fluids 11: 669-671. 